\title{
Effect of Relative Humidity on Aerosol Generation through Experiments at Low Concentrations of Gaseous Nitric Acid and Ammonia
}

\author{
Hitomi Kobara $^{1 *}$, Koji Takeuchi ${ }^{1}$ and Takashi Ibusuki ${ }^{2}$ \\ ${ }^{1}$ National Institute of Advanced Industrial Science and Technology, AIST, 16-1 Onogawa, \\ Tsukuba, Ibaraki 305-8569, Japan \\ 2 Japan Environmental Management Association for Industry
}

\begin{abstract}
Particle generation of ammonium nitrate from gaseous nitric acid and ammonia at low concentrations (100-600 ppbv) was investigated using a flow-type reactor with a silanized inner wall for deactivation. The particle number concentration of the generated aerosols was maximum at a constant relative humidity $(\mathrm{RH})$ of around $60 \%$ in experiments at different gas concentrations. The RH of $60 \%$ coincides with the deliquescence relative humidity (DRH) of ammonium nitrate, and the physical state of particles is thought to be different below and above DRH. The size distribution of the particles was greatly affected by the $\mathrm{RH}$. The $\mathrm{NH}_{4} \mathrm{NO}_{3}$ content in the wet particles was measured and compared with the value derived from the hydration-dehydration cycle. This report provides a simple and convenient method to generate $\mathrm{NH}_{4} \mathrm{NO}_{3}$ particles.
\end{abstract}

Keywords: Deliquescence relative humidity; Ammonium nitrate; Particle generation.

*Corresponding author. Tel: +81-29-861-8450; Fax: +81-29-861-8252

E-mail address: h-kobara@aist.go.jp 


\section{INTRODUCTION}

Atmospheric aerosols are attracting attention because of their use as a global material through their generation, conversion and removal processes, as well as their impact on the climate due to the effect of the changing albedo (Charlson and Wigley, 1994). Atmospheric aerosols are classified into primary particles and secondary particles. There are many uncertain areas (particle generation and growth mechanisms, chemical component, gas-particle balance, etc.) especially with secondary particles, which are generated by gas-to-particle conversion in the atmosphere. Most secondary particles are fine particles $\left(\mathrm{d}_{\mathrm{p}}<1 \mu \mathrm{m}\right)$ and their lifetime in the atmosphere is sufficient to contribute to a number of physical and chemical processes.

Ammonium nitrate is a major component of atmospheric aerosols, and secondary $\mathrm{NH}_{4} \mathrm{NO}_{3}$ particles from the reaction of gaseous $\mathrm{HNO}_{3}$ with $\mathrm{NH}_{3}$ in the atmosphere have been reported (Barthelmie and Pryor, 1988; Makar et al., 1998). Nitric acid in the atmosphere is produced from $\mathrm{NO}_{\mathrm{x}}$ by gas-phase oxidation reactions in the atmosphere (Chang et al., 1979; Spicer, 1982). For the dissociation equilibrium of nitrate in the gas phase, some experimental and theoretical studies have been conducted by considering atmospheric conditions (Stelson et al., 1979; Larson and Taylor, 1983; Bai et al., 1995). Olszyna et al. (1976) examined the particle generation of ammonium nitrate through a reaction between ammonia (84-1440 mtorr) and ozone (9-130 mtorr). It was shown that nitric acid first reacted with ammonia to give ammonium nitrate particles, and that the rate of particle generation increased by adding water vapor to the reaction system. Raes et al. (1990) studied ammonium nitrate particle generation and growth by photo irradiating a reaction gas mixture containing $\mathrm{NO}_{2}(50 \mathrm{ppmv})$ and $\mathrm{NH}_{3}(20-100$ ppmv) with a flow-type reactor. It was demonstrated that the classical Becker-Döing theory describes the particle generation process under the conditions in which excess ammonia was present.

The results of box-model calculation for SPM (Suspended Particulate Matters) concentration are in good agreement with those of the monitoring study when the effect of humidity is included (Winkler, 1973; Mizuno and Kaneyasu, 1994). However, experimental studies on the effects of humidity have not been conducted under conditions of low concentration reaction gases close to atmospheric level. One reason may be the difficulty in minimizing the loss of gases and particles due to their adsorption onto the wall surface of the reactors. This paper reports ammonium nitrate particle generation using a flow-type reactor with silane treatment, which makes it possible to keep the concentration of reaction gases at sub-ppm level. This system can be applied to a nitrate particle-supplying method for atmospheric chemistry experiments. 


\section{METHODS}

The schematic illustration of the experimental apparatus is shown in Fig. 1. A flow-type reactor consists of three Pyrex glass tubes $(11 \mathrm{~cm}$ in diameter, $40 \mathrm{~cm}$ in height) and Teflon connectors. The volume of the reactor is about $11 \times 10^{-3} \mathrm{~m}^{3}$. To prevent the adsorption of the reactive species onto the wall surface, the glass surface of the reactor was deactivated as follows: the inner wall was 1) soaked in an aqueous sulfuric acid solution (25\%) and dried, 2) treated with a solution of $\left(\mathrm{CH}_{3}\right)_{2} \mathrm{SiCl}_{2}$ (Shin-etsu Kagaku Co.) (5\%) in benzene for 10 minutes and dried, and 3) rinsed with anhydrous methanol and dried.

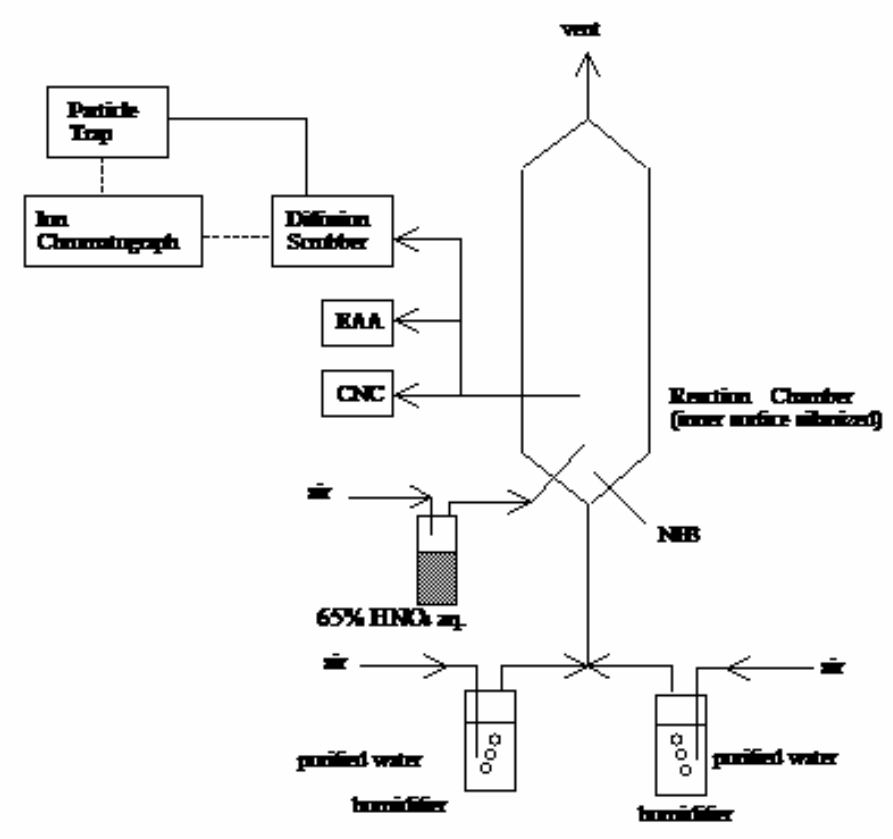

Fig. 1. Schematic diagram of experimental apparatus for aerosol formation.

Two nozzles (Pyrex glass: the surface was also deactivated) for introducing reaction gases are installed near the bottom of the reactor. Purified air $\left(7 \times 10^{-3} \mathrm{~m}^{3} / \mathrm{min}\right)$ is fed from the bottom of the reactor to dilute and mix reaction gases. Part of the purified air supplied with an STEC Model SGPU-21 air purifier is passed through a portion of the deionized water to control the humidity of the reaction gas. To ensure that the reaction gases were completely mixed, ethylene and air were introduced into the reactor through the nozzles, and the gas mixture was sampled from the sampling ports. The sample gas was analyzed by a gas chromatograph with an FID (Flame Ionization Detector) detector. The ethylene was uniformly and accurately diluted with air to the intended concentrations at the top of the nozzles. The outlet of the reactor opens at a hood, so the pressure in the flow-reactor was kept at atmospheric pressure. All experiments were carried out at room temperature $\left(25^{\circ} \mathrm{C}\right)$. 
A standard gas mixture of ammonia- $\mathrm{N}_{2}$ in a cylinder (Takachiho Kagaku Co.) was used for this experiment. Concentrated nitric acid is an azeotropic mixture at about $36 \mathrm{~mol} \%$ (66 wt\%), in which the concentration of nitric acid in the gas phase is equal to that of liquid phase. A solution of $65 \%$ aqueous nitric acid $(20 \mathrm{~mL}$, reagent grade, Wako Chemical Co.) was placed in a glass cylinder chilled at $5.0 \pm 0.05^{\circ} \mathrm{C}$. Purified air $(1.55-7.75 \mathrm{~mL} / \mathrm{min})$ was passed over the nitric acid solution to obtain gaseous nitric acid. This method can supply gaseous nitric acid stably over several weeks. The concentration of nitric acid was checked as follows: nitric acid was reduced to $\mathrm{NO}_{\mathrm{x}}$ by passing it through a gold tube converter with carbon monoxide as a reductant (reduction efficiency: more than 99.5\%), and the $\mathrm{NO}_{\mathrm{x}}$ generated was monitored by a ThermoElectron Model $42 \mathrm{~S}$ chemiluminescence $\mathrm{NO}_{\mathrm{x}}$ analyzer. The concentration of gaseous nitric acid and ammonia in the reaction gases ranged from $100-600 \mathrm{ppb}$, and the humidity was controlled from $0-95 \%$ relative humidity $(\mathrm{RH})$.

The number concentration of generated particles was counted with a TSI Model 3022 condensation nucleus counter (CNC), which can detect particles as small as $0.01 \mu \mathrm{m}$ in diameter. The size distribution of particles was measured from 0.018 to $0.1 \mu \mathrm{m}$ in diameter with an electrical aerosol analyzer (EAA, Nihon Kanomax Model 3030).

A diffusion scrubber (Yokogawa Analytical Systems), which collects gaseous species selectively based on the difference in diffusion coefficient between molecules and particles, was used to remove gaseous $\mathrm{HNO}_{3}$ and $\mathrm{NH}_{3}$ from the sample gas (Kobara et al., 1997). Particulate matter was collected with two midget impingers connected after the scrubber, then ions in the particles were analyzed with an ion chromatograph (Yokogawa Analytical Systems, IC 7000D). An efficiency of particle collection was $>99 \%$ since two impingers were connected in tandem, and the material balance was confirmed (Kobara et al., 1997). An adhesion of particles on the inner wall of the scrubber will be described in Results and Discussion.

\section{RESULTS AND DISCUSSION}

\section{Deactivation treatment to prevent adsorption}

There are many polar hydroxyl groups on the surface of the glass, and the adsorption of reactive species, such as $\mathrm{O}_{3}, \mathrm{NO}, \mathrm{NO}_{2}$, etc., by surface hydroxyl groups has been reported (Supina et al., 1966). Nitric acid and ammonia may be strongly adsorbed, and the loss cannot be neglected in this experiment where the concentration of the gases is very low. When the surface of the glass was washed with sulfuric acid and treated with $\left(\mathrm{CH}_{3}\right)_{2} \mathrm{SiCl}_{2}$ and then rinsed with anhydrous methanol, the surface $\mathrm{OH}$ groups of the glass were converted to -O-Si $\left(\mathrm{CH}_{3}\right)_{2}\left(\mathrm{OCH}_{3}\right)(\mathrm{Ottenstein,} \mathrm{1968)}$.

When gaseous nitric acid or ammonia was introduced into the flow reactor from the bottom after this treatment, the concentrations of the gases were the same at each sampling point. It is confirmed 
that the adsorption of nitric acid and ammonia onto the inner wall of the reactor is entirely prevented with this treatment.

\section{Measured particle number and size distribution}

No particles $\left(\leq 1 / \mathrm{cm}^{3}\right)$ were detected when nitric acid, ammonia or water at different concentrations were introduced separately into the reactor. Gaseous nitric acid or ammonia did not produce particles even under humid conditions. When nitric acid and ammonia coexisted, remarkable particle generation was observed. The concentration of generated particles increased by increasing the concentration of nitric acid or ammonia. Particle concentration was constant, independent of the sampling points. These results indicate that aerosol generation reached a state of equilibrium at the first sampling point due to the very high reaction rate.

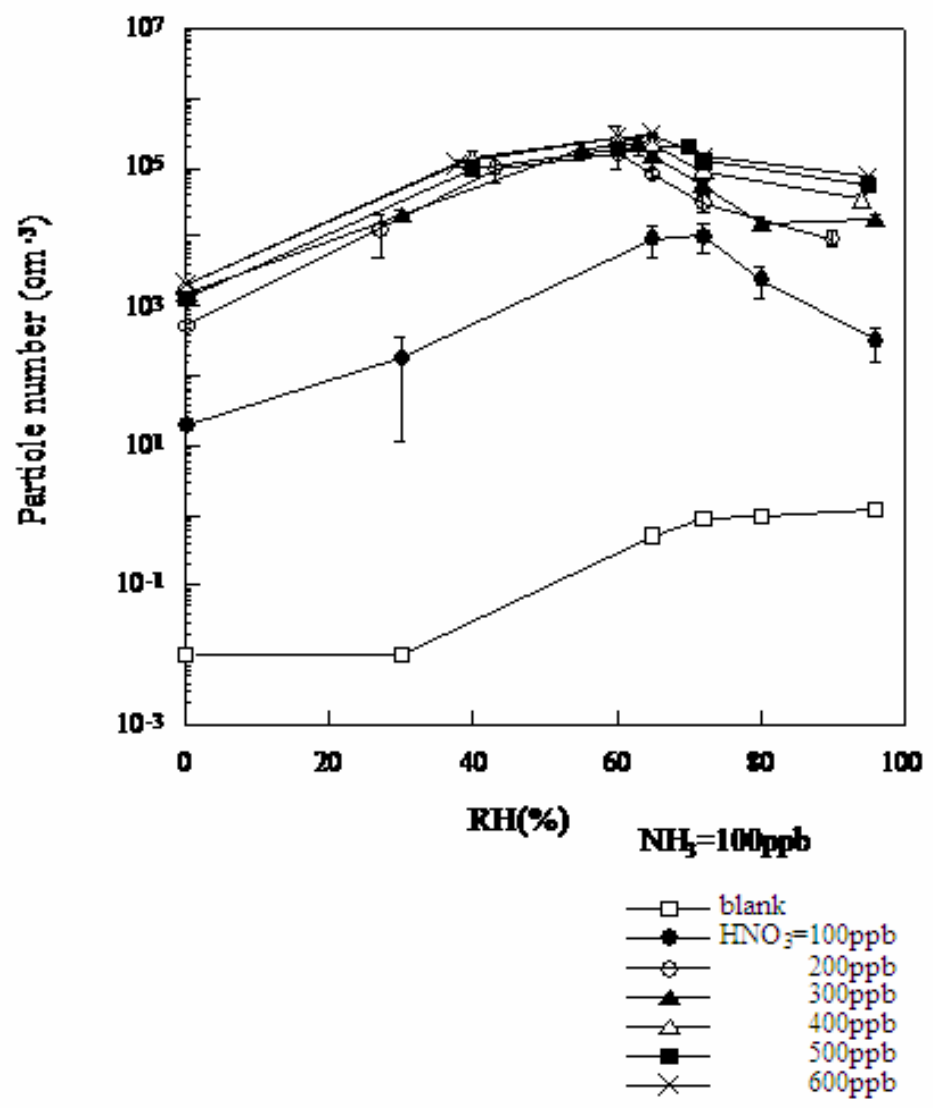

Fig. 2. Particle number concentration generated from gaseous nitric acid and ammonia. $\left[\mathrm{NH}_{3}\right]=$ $100 \mathrm{ppb},\left[\mathrm{HNO}_{3}\right]=100-600 \mathrm{ppb}, 25^{\circ} \mathrm{C}$.

When the RH was changed from 0 to $90 \%$ in constant concentrations of nitric acid and ammonia, the maximum number concentration of generated particles appeared at about an $\mathrm{RH}$ of $60 \%$, as shown in Fig. 2. The maximum number concentration was also observed at the same humidity, 
regardless of the concentration of nitric acid and ammonia. The deliquescence relative humidity (DRH) of ammonium nitrate has an $\mathrm{RH}$ of $62 \%$ at $25^{\circ} \mathrm{C}$ (Hidy, 1984), and the peak in the particle number observed in this measurement is in agreement with the DRH.

To clarify the effect of humidity on particle generation and growth, the size distribution of the generated particles was measured at an $\mathrm{RH}$ of $40 \%$ and $70 \%$. When the concentrations of gaseous nitric acid and ammonia were both $100 \mathrm{ppb}$, the size distribution could not be measured because the particle concentration was too low. Therefore, conditions in which $\left[\mathrm{HNO}_{3}\right]=200 \mathrm{ppb}$ and $\left[\mathrm{NH}_{3}\right]=$ $100 \mathrm{ppb}$ were selected as the second-lowest concentration of the reaction gas. Fig. 3 shows the results of the size distribution measurement. At an $\mathrm{RH}$ of $40 \%$, more than $75 \%$ of the generated particles were smaller than $0.056 \mu \mathrm{m}$ in diameter, and the particle concentration decreased with the increase in particle size as shown in Fig. 3(a). These results show that particles may grow only to a comparatively small size when solid particles are present. This agrees with the interpretation that particle growth does not occur under conditions below the DRH (Zufall et al., 1998). On the other hand, the size distribution of particles generated at an $\mathrm{RH}$ of $70 \%$ showed a peak in the diameter range of 0.056 to $0.1 \mu \mathrm{m}$ (Fig. 3(b)).
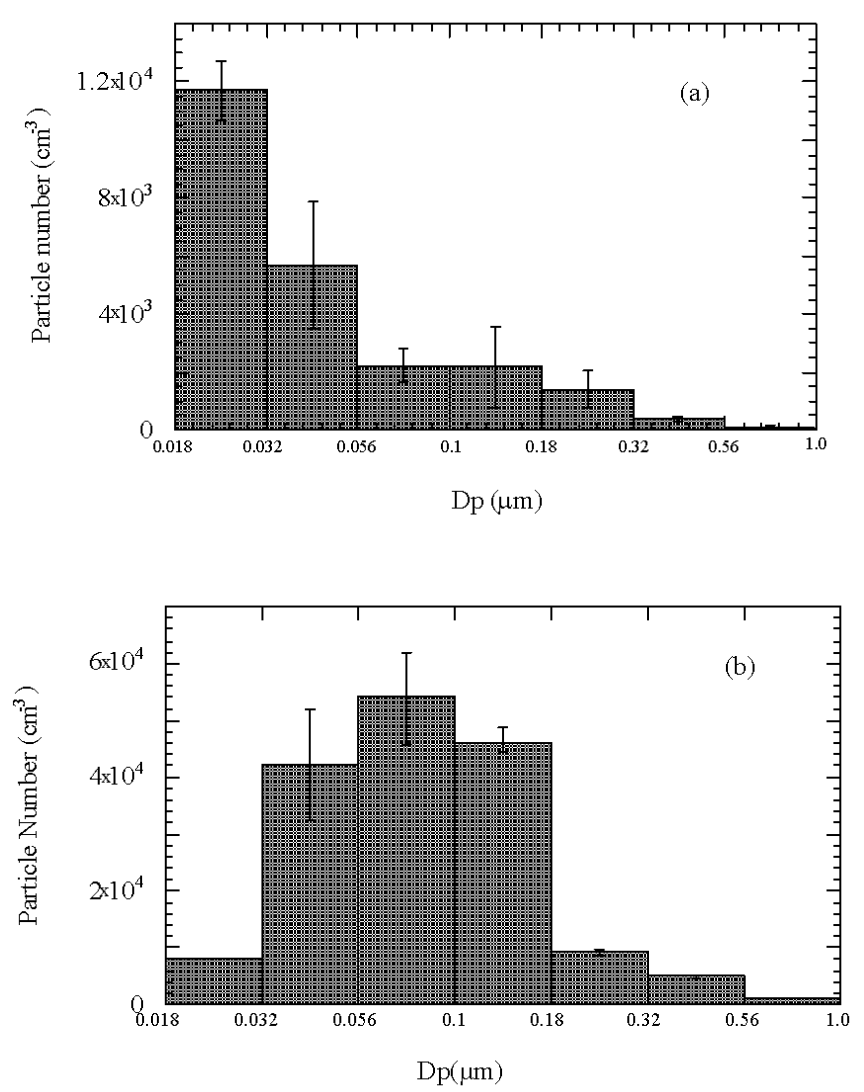

Fig. 3. Particle size distribution generated from gaseous nitric acid and ammonia. $\left[\mathrm{NH}_{3}\right]=100 \mathrm{ppb}$, $\left[\mathrm{HNO}_{3}\right]=200 \mathrm{ppb}, 25{ }^{\circ} \mathrm{C}$ (a) $\mathrm{RH} 40 \%$, (b) $\mathrm{RH} 70 \%$ 
As shown in Fig. 2, particle number concentration decreases with $\mathrm{RH}$ over $60 \%$, while it decreases with $\mathrm{RH}$ up to $60 \%$. This particle generation reaction is a nitric acid-ammonia-water ternary system of aerosol formation. $\mathrm{NH}_{4} \mathrm{NO}_{3}$ particles involving water crystallization are produced under the condition in which the $\mathrm{NH}_{4} \mathrm{NO}_{3}$ particle exists as a solid. $\mathrm{RH}$ increase in the reaction system equals the increase in water molecules, which act as an adhesive between the nitric acid and ammonia. This results in increased embryo-generation frequencies. Particle number concentration at $\mathrm{RH}<60 \%$ in Fig. 2 shows the increase of particles large enough to be detected by CNC. However, instead of embryo generation occurring under high RH conditions in which $\mathrm{NH}_{4} \mathrm{NO}_{3}$ is in liquid droplet form, particles apparently become larger through particle coagulation, while the number of particles decreases.

The ammonium nitrate concentration in the particles was measured by using a diffusion scrubber. The particles were removed selectively because of the difference in the diffusion coefficients between gaseous species and particulate matter. Particles that passed through the diffusion scrubber were absorbed by the water in the impingers. $\mathrm{NH}_{4}{ }^{+}$and $\mathrm{NO}_{3}{ }^{-}$concentrations were analyzed by ion chromatography, and the amount of nitric acid and ammonia in the particle phase was determined. Total volume concentrations at $\mathrm{RH} 40 \%$ and $70 \%, \mathrm{~V}_{40}$ and $\mathrm{V}_{70}$, were calculated by the size distributions. For liquid droplets at $\mathrm{RH} 70 \%, \mathrm{NH}_{4} \mathrm{NO}_{3}$ concentration in particles was determined by particle volume and ion concentration, followed by the calculation of the number of water molecules in liquid droplets. Moles $\mathrm{H}_{2} \mathrm{O} /$ Moles $\mathrm{NH}_{4} \mathrm{NO}_{3}$ were determined by the constituent in the liquid droplets. The $\mathrm{NH}_{4} \mathrm{NO}_{3}$ concentration in the liquid droplets generated at an $\mathrm{RH}$ of $70 \%$ was $14.3 \mathrm{~mol} / \mathrm{L}$.

The molecule ratio in the particles and the total volume ratio of wet to dry particle, $V_{70}$ and $V_{40}$, are listed in Table 1. The size distributions were measured ranging in diameter from 0.018-1.0 $\mu \mathrm{m}$ by EAA. Particle number concentrations were measured for particles larger than $0.01 \mu \mathrm{m}$ in diameter; therefore, no size information was obtained for particles $0.01-0.018 \mu \mathrm{m}$ in diameter. However, the number concentration of particles from 0.01 to $0.18 \mu \mathrm{m}$ was less than about $8 \times 10^{4}$ $\mathrm{cm}^{-3}$ according to a comparison of particle number and size distribution data (Fig. 2 and Fig. 3(a)). The contribution of particles smaller than $0.018 \mu \mathrm{m}$ should be smaller at $70 \%$ RH (Fig. 2 and Fig. 3(b)). The volume of particles between 0.01 and $0.018 \mu \mathrm{m}$ was less than $1 \%$ of the total volume of particles. Therefore, for the calculation of $\mathrm{V}_{40}$ and $\mathrm{V}_{70}$, the contribution of particles smaller than $0.018 \mathrm{~mm}$ was judged to be negligible.

Materials adhered onto the scrubber's inner wall were $0.45 \mathrm{nmol}$ of nitric acid and $0.52 \mathrm{nmol}$ of ammonia when $1 \times 10^{-2} \mathrm{~m}^{3}$ of the sample gas was passed through the scrubber. These amounts corresponded to $10.8 \%$ and $12.1 \%$ of nucleated nitric acid and ammonia at RH $70 \%$, respectively. At RH $40 \%$, the amount of adhered nitric acid and ammonia was $4.4 \%$ and $4.8 \%$ of nucleated substances with $1 \times 10^{-2} \mathrm{~m}^{3}$ of the sample gas. The amount of ammonium nitrate in the particles 
was determined by considering these amounts of adhered species during the transfer from the gas to particulate phase.

As described before, ammonium nitrate is a deliquescent salt. The ratio Moles $\mathrm{H}_{2} \mathrm{O} /$ Moles $\mathrm{NH}_{4} \mathrm{NO}_{3}$ was determined to be about 3.3, and the mass ratio of liquid droplet to dry particle $\mathrm{M} / \mathrm{Mo}$ was about 1.7 at an $\mathrm{RH}$ of $70 \%$ using thermodynamic model prediction and hydration-dehydration experiments (Clegg et al., 1998; Lightstone et al., 2000). If $\mathrm{HNO}_{3}$ and $\mathrm{NH}_{3}$ first form crystalline particles followed by $\mathrm{H}_{2} \mathrm{O}$ uptake under humid conditions, the ratio of Moles $\mathrm{H}_{2} \mathrm{O} / \mathrm{Moles} \mathrm{NH}_{4} \mathrm{NO}_{3}$ should be 3.3, the same as the ratio in the hydration of the crystals shown in Table 1. However, the ratio of Moles $\mathrm{H}_{2} \mathrm{O}$ /Moles $\mathrm{NH}_{4} \mathrm{NO}_{3}$ of the particles was 3.9 in this experiment, and particles contained more water than expected from the hydration-dehydration loop (deliquescence). The water content in the droplets and the volume ratio of liquid droplet to dry particle are also greater than predicted by the deliquescence-efflorescence loop. This means that the initial step of particle generation is not the formation of crystalline particles. $\mathrm{H}_{2} \mathrm{O}$ molecules are incorporated into the particles when $\mathrm{HNO}_{3}$ and $\mathrm{NH}_{3}$ aggregate through collision with each other. It is considered that particle generation at a high RH is promoted by the capturing of water and coagulation, which results in large Moles $\mathrm{H}_{2} \mathrm{O}$ /Moles $\mathrm{NH}_{4} \mathrm{NO}_{3}$ and $\mathrm{M} / \mathrm{Mo}$ values in the particles. To explain the difference in particle generation processes at different levels of humidity, nucleation rates can be estimated using the conditions in this experiment.

Table 1 Moles $\mathrm{H}_{2} \mathrm{O}$ /Moles $\mathrm{NH}_{4} \mathrm{NO}_{3}$ and total volume ratio of wet particles to dry particles $\left(\mathrm{V}_{70} / \mathrm{V}_{40}\right)$ of particles generated in this experiment, with Moles $\mathrm{H}_{2} \mathrm{O} / \mathrm{Moles} \mathrm{NH}_{4} \mathrm{NO}_{3}$ and mass ratio of solution droplet to dry particle $(\mathrm{M} / \mathrm{Mo})$ of $\mathrm{NH}_{4} \mathrm{NO}_{3}$ salt in hydration/dehydration cycle.

\begin{tabular}{lcc}
\hline & This experiment & $\mathrm{NH}_{4} \mathrm{NO}_{3}$ salt in hydration/dehydration cycle \\
\hline Moles $\mathrm{H}_{2} \mathrm{O} /$ Moles $\mathrm{NH}_{4} \mathrm{NO}_{3}$ & 3.9 & 3.3 \\
$\mathrm{~V}_{70} / \mathrm{V}_{40}$ & 6.0 & 1.7 \\
$\mathrm{M} / \mathrm{Mo}$ & & \\
\hline
\end{tabular}

\section{Relation to the nucleation model}

In gas-phase homogeneous nucleation, the nucleation rate is generally represented as

$$
\begin{aligned}
& \mathrm{J}=\mathrm{A} \cdot \exp \left(-\Delta \mathrm{G}^{*} / \mathrm{kT}\right) \\
& \mathrm{G}^{*}=16 \pi \gamma^{3} v^{2} / 3(\mathrm{RT} \ln S)^{2}
\end{aligned}
$$

where $\mathrm{A}$ is the exponential prefactor that represents the collision frequency for a molecule to transition to the solid or liquid phase, $\Delta \mathrm{G}^{*}$ is the barrier height at nucleation, $\mathrm{k}$ is Boltzmann's 
constant, $\mathrm{T}$ is the Kelvin temperature, $\gamma$ is the surface tension, $v$ is the molar volume of the particles and $\mathrm{S}$ is the saturation ratio.

In the system, including chemical reactions, reaction enthalpies are involved in the free energy (Kiang, 1975):

$$
\mathrm{G}^{\prime}=\Delta \mathrm{G}^{*} \pm \Delta \mathrm{H}
$$

Therefore, $\mathrm{J}$ is transformed into:

$$
\begin{aligned}
\mathrm{J} & =\mathrm{A} \cdot \exp \left\{-\left(\Delta \mathrm{G}^{*} \pm \Delta \mathrm{H}\right) / \mathrm{kT}\right\} \\
& =\mathrm{A} \cdot \exp \left(-\Delta \mathrm{G}^{*} / \mathrm{kT}\right) \cdot \exp \{-( \pm \Delta \mathrm{H}) / \mathrm{kT}\} \\
& =\mathrm{A}^{\prime} \cdot \exp \left(-\Delta \mathrm{G}^{*} / \mathrm{kT}\right)
\end{aligned}
$$

where $A^{\prime}=A \cdot \exp ( \pm \Delta H / k T)^{-1}$

The value of $-\Delta \mathrm{G}^{*} / \mathrm{kT}$ can be calculated by using parameters of solid $\mathrm{NH}_{4} \mathrm{NO}_{3}$ (Rehbinder, 1926; Stelson et al., 1982a; Raes et al., 1990; Weast et al., 1990a) at an RH less than the DRH, and aqueous $\mathrm{NH}_{4} \mathrm{NO}_{3}$ (Stelson et al., 1982b; Söhnel and Novotny, 1985; Weast et al., 1990b) at an RH greater than the DRH. In this experiment, the generated particle number concentration is $5 \times 10^{4}$ $\mathrm{cm}^{-3}$ under an $\mathrm{RH}$ of $40 \%,\left[\mathrm{HNO}_{3}\right]=200 \mathrm{ppb}$ and $\left[\mathrm{NH}_{3}\right]=100 \mathrm{ppb}$. Therefore, exponential prefactor $\mathrm{A}^{\prime}$ including the thermodynamic parameter with the chemical reaction is estimated to be $\mathrm{A}^{\prime} \approx 8.85 \times 10^{22}$. $\mathrm{A}^{\prime}$ at an $\mathrm{RH}$ of $70 \%$ under the same $\mathrm{HNO}_{3}$ and $\mathrm{NH}_{3}$ concentration is $\approx 3.27 \times 10^{32}$. The difference between these two reaction conditions is only the water vapor content $(\mathrm{RH} 40 \%$ / $\mathrm{RH} 70 \%$ ), but the A' value at an $\mathrm{RH}$ of $70 \%$ is larger than that at a $40 \% \mathrm{RH}$; up to about 10 orders of magnitude. This $A^{\prime}$ difference shows that the collision frequencies of molecules increase exponentially with increasing water molecule concentrations in the nitric acid-ammonia-water ternary system. It is ascertained that the high probability of $\mathrm{H}_{2} \mathrm{O}$ collision with $\mathrm{HNO}_{3}$ and $\mathrm{NH}_{3}$ leads to the formation of water-rich droplets. Total particle volume ratio of $\mathrm{RH} 70 \%$ to $40 \%$ is $\mathrm{V}_{70} / \mathrm{V}_{40}=6.0$, while particle number concentrations are comparable. Particle nuclei generate more at RH $70 \%$ than at $40 \%$ because of high molecular collision frequencies. Particle volume becomes larger by particle nuclei coagulation, as well as gas molecule condensation on the surface of particles.

\section{CONCLUSION}

A flow-type reactor was used to experiment with particle generation from gaseous nitric acid and ammonia. With the inactivation of the reactor surface, loss of gaseous species and particulate matter by adsorption hardly occurred, so observation of particle generation from a low 
concentration of gaseous nitric acid and ammonia could be conducted. The particle generation of ammonium nitrate was greatly affected by relative humidity, and the size distribution was quite different below and above the DRH of ammonium nitrate. The method in this report is a simple and convenient way to supply $\mathrm{NH}_{4} \mathrm{NO}_{3}$ particles; e.g., useful for aerosol experiments and standard examinations. Water content in liquid droplets was greater than the value of the equilibrium growth curve of ammonium nitrate salt with water deposits. The degree of swelling of the particles was also higher than indicated from the hydration-dehydration loop. The collision frequency of gaseous species was estimated, and it was clarified that it increased 10 orders of magnitude as the relative humidity increased from 40 to $70 \%$. $\mathrm{NH}_{4} \mathrm{NO}_{3}$ particle generation under conditions of high humidity was promoted more than thermodynamic equilibrium due to the uptake of water when $\mathrm{HNO}_{3}$ and $\mathrm{NH}_{3}$ aggregated. This effect of humidity on the particle formation process should be considered, for example, when an atmospheric model is developed.

\section{ACKNOWLEDGMENTS}

The authors thank Dr. Otsuka of Saitama University for his advice on the generation of low concentration gaseous nitric acid.

\section{REFERENCES}

Bai, H., Lu, C. and Ling, Y. M. (1995). A Theoretical Study on the Evaporation of Dry Ammonium Chloride and Ammonium Nitrate Aerosols. Atmos. Environ. 29(3): 313-321.

Barthelmie, R.J. and Pryor, S.C. (1998). Implications of Ammonia Emissions for Fine Aerosol Formation and Visibility Impairment: A 10 Case Study from the Lower Fraser Valley, British Columbia. Atmos. Environ. 32, 3: 345-352

Chang, T.Y., Norbeck, J.M. and Weinstock, B. (1979). An Estimate of the $\mathrm{NO}_{\mathrm{x}}$ Removal Rate in an Urban Atmosphere. Environ. Sci. Technol. 13: 1534-1537.

Charlson, R.J. and Wigley, T.M.L. (1994). Sulfate Aerosol and Climate Change. Sci. Am. February: 48-57.

Clegg, S.L., Brimblecombe, P. and Wexler, A.S. (1998). Thermodynamic Model of the System $\mathrm{H}^{+}-\mathrm{NH}_{4}{ }^{+}-\mathrm{Na}^{+}-\mathrm{SO}_{4}{ }^{2-}-\mathrm{NO}_{3}{ }^{-}-\mathrm{Cl}^{-}-\mathrm{H}_{2} \mathrm{O}$ at $298.15 \mathrm{~K}$. J. Phys. Chem. 102: 2137-2154.

Hidy, G.M. (1984). Aerosols, p. 75, Academic Press, Inc., Orlando, Florida.

Kiang, C.S. and Cadle, R.D. (1975). Ternary Nucleation Applied to Gas to Particle Conversion. J. Aerosol Sci. 6: 465-474.

Kobara, H., Takeuchi, K. and Ibusuki, T. (1997). Collection of Low-Concentration Ammonia and Nitric Acid Gas Using a Diffusion Scrubber and its Application to the Separation of Particulate Matter. Bunseki Kagaku 46, 11: 881-886. 
Larson, T.V. and Taylor, G.S. (1983). On the Evaporation of Ammonium Nitrate Aerosol. Atmos. Environ. 17(12): 2489-2495.

Lightstone, J.M., Onasch, T.B., Imre, D. and Oatis, S. (2000). Deliquescence, Efflorescence, and Water Activity in Ammonium Nitrate and Mixed Ammonium Nitrate/Succinic Acid Microparticles. J. Phys. Chem. A, 104: 9337-9346.

Makar, P.A., Wiebe, H.A., Staebler, R.M., Li, S.M. and Anlauf, K. (1998). Measurement and Modeling of Particle Nitrate Formation. J. Geophys. Res. 103, D11: 13095-13110.

Mizuno, T. and Kaneyasu, N. (1994). Simulation of SPM Concentration Taking into Account the Effect of Liquid Water. J. Jpn. Soc. Air Pollut. 29(6): 340-350.

Olszyna, K.J., de Pena, R.G. and Heicklen, J. (1976). Kinetics of Particle Growth VII. $\mathrm{NH}_{4} \mathrm{NO}_{3}$ from the $\mathrm{NH}_{3}-\mathrm{O}_{3}$ Reaction on the Presence of Air and Water Vapor. Int. J. Chem. Kinet. VIII: 357-379.

Ottenstein, D.M. (1968). Comparison of Support Deactivation in Gas Chromatography. J. Gas Chromatogr. 6: 129-134.

Raes, F., Kodas, T.K. and Friedlander, S.K. (1990). Aerosol Formation by a Reversible Chemical Reaction: Laser Induced $\mathrm{NH}_{4} \mathrm{NO}_{3}$ Aerosol Formation in a Tubular Reactor. Aerosol Sci. Tech. 12: 856-868.

Rehbinder, P. (1926). Wasser Als Oberflachenaktiver Stoff. Oberflachenaktivitat Und Adsorptionskrafte. II. Z. Phys. Chem. 121: 103-126.

Söhnel, O. and Novotny, P. (1985). Densities of Aqueous Solutions of Inorganic Substances. Physical Sciences Data 22, Elsevier, Amsterdam.

Spicer, C.W. (1982). Nitrogen Oxide Reactions in the Urban Plume of Boston. Science, 215: 1095-1097.

Stelson, A.W., Friedlander, S.K. and Seinfeld, J.H. (1979). A Note on the Equilibrium Relationship between Ammonia and Nitric Acid and Particulate Ammonium Nitrate. Atmos. Environ. 13: 369-371.

Stelson, A.W. and Seinfeld, J.H. (1982a). Relative Humidity and Temperature Dependence of the Ammonium Nitrate Dissociation constant. Atmos. Environ. 16(5): 983-992.

Stelson, A.W. and Seinfeld, J.H. (1982b). Relative Humidity and pH Dependence of the Vapor Pressure of Ammonium Nitrate-Nitric Acid Solutions at $25^{\circ} \mathrm{C}$. Atmos. Environ. 16(5): 993-1000 Supina, W.R., Henly, R.S. and Kruppa, R.F. (1966). Silane Treatment of Solid Supports for Gas Chromatography. J. Am. Oil Chem. Soc. 43: 202A-232A.

Weast, R.C., Lide, D.R., Astle, M.J. and Beyer, W.H. (1990a). CRC Handbook of Chemistry and Physics, B-71, CRC Press, Inc., Boca Raton, Florida.

Weast, R.C., Lide, D. R., Astle, M. J. and Beyer, W. H. (1990b). CRC Handbook of Chemistry and Physics, F-33, CRC Press, Inc., Boca Raton, Florida.

Winkler, P (1973). The Growth of Atmospheric Aerosol Particles as a Function of the Relative 
Humidity II. An Improved Concept of Mixed Nuclei. J. Aerosol Sci. 4: 373-387.

Zufall, M.J., Bergin, M.H. and Davidson, C.I. (1998). Effect of Non-Equilibrium Hygroscopic Growth of $\left(\mathrm{NH}_{4}\right)_{2} \mathrm{SO}_{4}$ on Dry Deposition to Water Surfaces. Environ. Sci. Technol. 32: 584-590.

Received for review, October 19, 2006 Accepted, February 17, 2007 